\title{
A cross-sectional study on urogenital schistosomiasis in children; haematuria and proteinuria as diagnostic indicators in an endemic rural area of Nigeria
}

Olajumoke Morenikeji ${ }^{* 1}$, Junaid Quazim ${ }^{1}$, Claire Omoregie ${ }^{1}$, Adesola Hassan ${ }^{1}$, Roseangela Nwuba ${ }^{1}$, Chiaka Anumudu ${ }^{1}$, Sunday Adejuwon², Oyetunde Salawu ${ }^{1}$, Ayodele Jegede ${ }^{3}$, Alexander Odaibo ${ }^{1}$

1. Department of Zoology, University of Ibadan, Ibadan, Nigeria

2. Department of Anatomy, College of Medicine, University of Ibadan, Nigeria

3. Department of Medical Sociology, University of Ibadan, Ibadan, Nigeria

\begin{abstract}
Background: Rapid and accurate diagnosis is necessary for the management of schistosomiasis in endemic areas.

Objective: To assess the burden of urogenital schistosomiasis and the diagnostic efficiency of morbidity indicators of the disease in an endemic rural community of Nigeria.

Methods: A cross-sectional school-based study was conducted. Urine samples of 487 pupils were screened microscopically for $S$. haematobium and tested for haematuria and proteinuria using chemical reagent strips.

Results: The prevalence and intensity of infection were $57.1 \%$ and $45.0 \mathrm{eggs} / 10 \mathrm{~mL}$ urine respectively. Prevalence of infection in male $(54.1 \%)$ and female $(60.3 \%)$ individuals showed no significant variation $(\mathrm{P}>0.05)$. However, prevalence of infection was age dependent with those in age groups 3-5 and 12-14 years having the least and highest prevalence of infection respectively $(\mathrm{P}<0.05)$. Microhaematuria and proteinuria varied significantly with ages of the pupils with least (14.0, $40.0 \%)$ and highest $(60.0,80.0 \%)$ prevalence recorded in age groups 3-5 and $15-19$ years respectively $(\mathrm{P}<0.05)$. Proteinuria showed higher sensitivity $(80.3 \%)$ compared to microhaematuria $(73.3 \%)$.

Conclusion: Schistosomiasis is highly endemic in the study area and the use of microhaematuria and proteinuria for mapping the infected population prior treatment could be adopted.
\end{abstract}

Key words: Schistosomaisis, haematuria, proteinuria, Nigeria

African Health Sciences 2014; 14(2):390-396

DOI: http://dx.doi.org/10.4314/ahs.v14i2.15

\section{Introduction}

Schistosomiasis is a chronic disease with high public health importance as 207 million people have been estimated to be infected worldwide ${ }^{1}$. Most recent estimate reported 50.8 million infected individuals in aged $\leq 20$ years in West Africa ${ }^{2}$ (Schur et al., 2011). Schistosomiasis has been widely reported in Nigeria ${ }^{3-6}$.

The implementation of programmes to controlschistosomiasis requires up-to-date information regarding the prevalence and distribution of the diseases? ${ }^{7}$. Rapid and indirect diagnostic methods have been suggested to aid quick mapping surveys in endemic regions ${ }^{8}$.

\section{Corresponding author:}

Morenikeji Olajumoke

Address: Parasitology Research Unit, Department of Zoology, University of Ibadan, Nigeria

E-mail: jumokemorenikeji@yahoo.co.uk Phone number: +2348055275915
This becomes important as rapid detection of diseased individuals is necessary for efficient intervention through mass drug administration in the areas. Some of the notable indicators of infection especially due to S. haematobium for rapid assessment are haematuria, proteinuria and leukocyturia.

Operational research studies in Nigeria and other African countries have shown these indicators as good morbidity indicators of $S$. haematobium infection and have been successfully used to identify school children requiring treatment and subsequently monitor control $^{9,10}$. However, the low sensitivities of these indicators to detect the diseased population especially in low endemic areas have raised some questions on the reliance of results obtained from such studies. An approach of combining two or more indicators has been developed to improve the diagnostic accuracy or efficiency ${ }^{10}$.

The present school-based study reports the prevalence of urogenital schistosomiasis and reliability of haematuria and proteinuria as diagnostic indicators of the disease in a rural endemic area of Nigeria. 
Materials and methods

\section{Study setting}

A cross-sectional school based study was conducted in Yewa North Central Primary School, Ijoun, Ogun State in the south-western part of Nigeria. Ijoun is a rural community with a heterogeneous population comprising the Yorubas, Fulanis, Igbos and few individuals from the Republic of Benin. The inhabitants depend on streams and rivers for their sources of water for domestic purposes. The snail intermediate hosts of $S$. haematobium have been discovered in the river bodies in the $\operatorname{area}^{11}$.

\section{Sample size and sampling procedures}

Sample size was calculated using the method described by Naing et al. ${ }^{12}$ A prevalence of $55 \%$ was used to compute the minimum sample size based on previous report on schistosomiasis in some other communities in the LGA ${ }^{13}$. The sample size arrived at was 380 with precision $0.05(5 \%)$ being the most suitable. The statistical power used was $80 \%$. A total of 541 school pupils were recruited but 487 and 432 pupils provided urine samples for microscopic examination and reagent strips screening respectively. Class to class recruitment procedure was adopted during which the pupils through the help of the class teacher were given urine sample bottles and were monitored for urine collection. Samples were collected between March and April, 2010.

\section{Data collection}

Clean and sterile universal urine containers were given to each of the pupils to collect samples of urine. Urine, $10-20 \mathrm{~mL}$, was collected at midday (10.00-14.00 hours) under the proper guide of the teachers and the research team. The urine containers were clearly labelled with the sample number assigned to each participant.

The freshly passed urine samples were inspected macroscopically for gross haematuria and then screened for microhaematuria and proteinuria using commercially available urine reagent strips (Medi-Test Combi 10, Standard Diagnostics Inc., Korea). The strip testing was performed in accordance with the manufacturer's instructions. The urinary protein content was recorded as negative $(<0.1 \mathrm{~g} / \mathrm{L}$ of urine), trace $(<0.3 \mathrm{~g} / \mathrm{L}), 1+$, $2+, 3+$ or $4+$. The symbols are intended to correlate as follows: +1 with $0.3 \mathrm{~g} / \mathrm{L},+2$ with $1.0 \mathrm{~g} / \mathrm{L},+3$ with $3.0 \mathrm{~g} / \mathrm{L}$ and +4 with $\geq 5.0 \mathrm{~g} / \mathrm{L}$. The samples were transported in a dark container to the laboratory and processed within 24 hours after collection. Each sample was well-mixed and $10 \mathrm{~mL}$ was withdrawn using clean, sterile plastic syringes. This was then centrifuged at $5000 \mathrm{rpm}$ for 5 minutes. The supernatant was decanted and the sediments were transferred to a clean slide and examined under a light microscope for eggs of $S$. baematobium using the $\mathrm{x} 10$ objective lens.

Intensity of infection was classified using Briand et al's modification of WHO recommendations ${ }^{14}$. Intensity of infection was thus categorized as no infection, light infection (1-9 egg/10mL of urine), moderate infection (10-49 eggs/10 $\mathrm{mL}$ of urine) and heavy infections ( $\geq 50 \mathrm{eggs} / 10 \mathrm{~mL}$ of urine). All the infected individuals were treated with single dose of 40 $\mathrm{mg} / \mathrm{kg}$ of praziquantel.

The older pupils were asked their ages while in case of uncertainty and in younger pupils, the class teachers were engaged who confirmed their ages by consulting the class register containing each pupil biodata. The age of each pupil was recorded against their names in the register created for the study.

\section{Quality control}

Urine samples collected were prevented from direct light penetration in order to avoid hatching of parasite eggs before microscopy examination. Parasite morphology and intensity was confirmed by another scientist during examination.

\section{Ethical considerations}

Ethical approval was obtained from the joint University of Ibadan/University College Hospital Ethical Review Board. Approval was also obtained from Ogun State Ministry of Health and the Ministry of Education. The community's leaders and the school's administrators were duly informed of the objectives and benefits of the study. The children parents were also invited to Parent Teacher Association (PTA) meeting during which they were briefed on the significance of the study. Written informed consent was obtained from them after a detailed explanation of the objectives of the study. Participant's personal information was treated private and was not divulged to third party. For example, sample bottles were identified only by a unique code allotted to them while every other information was recorded in the study's register.

\section{Inclusion and exclusion criteria}

All pupils with the exception of the very few ones who declined were recruited for the study. 


\section{Statistical analysis}

Data were entered into an Excel spreadsheet, checked for entry errors and transferred into SPSS for Windows (version 15.0, SPSS Inc, Chicago, USA) for analysis. The sensitivity (number of individuals with a positive rapid test/individuals with a positive reference test) and specificity (number of individuals with a negative rapid test/individuals with a negative reference test) were calculated for rapid tests (chemical reagent strips) compared to the gold standard (microsscopy was used as the reference test). Chi-square tests were applied to compare relative proportions of infections between genders and ages of the pupils. When analyzing for the effect of age, pupils were divided into 5 groups: aged $3-5,6-8,9-11,12-14$, and $\geq 15$ years. The intensity of infection measured by the parasite egg counts was logarithmically transformed into geometric mean. Student's t-test and ANOVA were used to determine significant differences in intensity of infection. $\mathrm{P}$ values $<0.05$ were considered significant.

\section{Results}

The overall prevalence and intensity of infection due to $S$. haematobium were $57.1 \%$ and $45.0 \mathrm{eggs} / 10 \mathrm{~mL}$ urine $(\mathrm{OR}=1.8, \mathrm{CI}=1.1-3.8)$ respectively. Prevalence of urogenital schistosomiasis varied significantly across age groups $(\mathrm{P}<0.05)$ with the least $(27.5 \%)(\mathrm{OR}=0.5$, $\mathrm{CI}=0.3-1.0)$ and highest prevalence (68.4\%) $(\mathrm{OR}=2.9$, $\mathrm{CI}=2.0-4.2)$ recorded in age groups 3-5 and 12-14 years respectively (Table 1).

Table 1. Age and sex related infection pattern

\begin{tabular}{llllllll}
\hline $\begin{array}{l}\text { Age } \\
\text { group } \\
\text { (years) }\end{array}$ & Sex & No. examined & $\begin{array}{l}\text { No. infected } \\
(\%)\end{array}$ & $\begin{array}{l}\text { Light infection } \\
(\%)\end{array}$ & $\begin{array}{l}\text { Moderate infection } \\
(\%)\end{array}$ & $\begin{array}{l}\text { Heavy infection } \\
(\%)\end{array}$ & OR(95\%CI) \\
\hline $3-5$ & M & 32 & $7(21.9)$ & $3(42.9)$ & $1(14.3)$ & $3(42.9)$ & $0.5(0.1-1.7)$ \\
& F & 19 & $7(36.8)$ & $2(28.6)$ & $0(0)$ & $5(71.4)$ & $2.1(0.6-7.3)$ \\
& T & 51 & $14(27.5)$ & $5(35.7)$ & $1(7.1)$ & $8(57.1)$ & $0.5(0.3-1.0)$ \\
$6-8$ & M & 65 & $33(50.8)$ & $7(21.2)$ & $14(42.2)$ & $12(36.4)$ & $1.4(0.7-2.8)$ \\
& F & 58 & $25(43.1)$ & $7(28.0)$ & $10(40.0)$ & $8(32.0)$ & $0.7(0.4-1.5)$ \\
& T & 123 & $58(47.2)$ & $14(24.1)$ & $24(41.4)$ & $20(34.5)$ & $1.2(0.8-1.8)$ \\
$9-11$ & M & 64 & $36(56.3)$ & $7(19.4)$ & $12(33.3)$ & $17(47.2)$ & $0.6(0.3-1.1)$ \\
& F & 72 & $50(69.4)$ & $8(16.0)$ & $13(26.0)$ & $29(58.0)$ & $1.8(0.9-3.6)$ \\
& T & 136 & $86(63.2)$ & $15(17.4)$ & $25(29.1)$ & $46(53.5)$ & $2.3(1.5-3.4)$ \\
$12-14$ & M & 81 & $52(64.2)$ & $3(5.8)$ & $20(38.5)$ & $29(55.8)$ & $0.7(0.3-1.3)$ \\
& F & 71 & $52(73.2)$ & $14(26.9)$ & $11(21.1)$ & $27(51.9)$ & $1.5(0.8-3.0)$ \\
& T & 152 & $104(68.4)$ & $17(16.4)$ & $31(29.8)$ & $56(53.9)$ & $2.9(2.0-4.2)$ \\
$\geq 15$ & M & 13 & $10(76.9)$ & $1(10.0)$ & $5(50.0)$ & $4(40.0)$ & $3.3(0.6-18.5)$ \\
& F & 12 & $6(50.0)$ & $1(16.7)$ & $1(16.7)$ & $4(66.7)$ & $0.3(0.1-1.7)$ \\
& T & 25 & $16(64.0)$ & $2(12.5)$ & $6(37.5)$ & $8(50.0)$ & $2.3(1.0-5.5)$ \\
Total & M & 255 & $138(54.1)$ & $21(15.2)$ & $52(37.7)$ & $65(47.1)$ & $0.8(0.5-1.1)$ \\
& F & 232 & $140(60.3)$ & $32(22.9)$ & $35(25.0)$ & $73(52.1)$ & $1.3(0.9-1.8)$ \\
& T & 487 & $278(57.1)$ & $53(19.1)$ & $87(31.3)$ & $138(49.6)$ & $1.8(1.1-3.8)$
\end{tabular}

Note: OR- odd ratio, CI- confidence interval

There was no gender difference in infection pattern ( $\mathrm{P}>0.05)$, however, more female participants $(60.3 \%)(\mathrm{OR}=0.8,0.5-1.1)$ were infected than the male participants $(54.1 \%)(\mathrm{OR}=1.3, \mathrm{CI}=0.9-1.8)$. The overall prevalence of microhaematuria was $50.0 \%$ and age related prevalence of microhaematuria was similar to what was observed in infection due to $S$. haematobium with the least $(14.0 \%)$ and highest $(60.0 \%)$ prevalence recorded in age groups 3-5 and 12-14 years respectively (Table 2). 
Table 2. Age and sex prevalence profiles of urogenital schistosomiasis morbidity indicators

\begin{tabular}{|c|c|c|c|c|c|c|}
\hline \multirow{2}{*}{$\begin{array}{l}\text { Agegroup } \\
\text { (years) }\end{array}$} & \multirow[t]{2}{*}{ Sex } & \multicolumn{2}{|c|}{ Macrohaematuria } & \multicolumn{2}{|c|}{ Microhaematuria } & \multirow{2}{*}{$\begin{array}{l}\text { Proteinuria } \\
\text { Prevalence } \\
(\%)\end{array}$} \\
\hline & & $\begin{array}{l}\text { No. } \\
\text { examined }\end{array}$ & $\begin{array}{l}\text { Prevalence } \\
(\%)\end{array}$ & $\begin{array}{l}\text { No. } \\
\text { examined }\end{array}$ & $\begin{array}{l}\text { Prevalence } \\
(\%)\end{array}$ & \\
\hline \multirow[t]{3}{*}{$3-5$} & $\bar{M}$ & 32 & $1(3.1)$ & 31 & $4(12.9)$ & $14(45.2)$ \\
\hline & $\mathrm{F}$ & 19 & $0(0.0)$ & 19 & $3(15.8)$ & $6(31.6)$ \\
\hline & $\mathrm{T}$ & 51 & $1(2.0)$ & 50 & $7(14.0)$ & $20(40.0)$ \\
\hline \multirow[t]{3}{*}{$6-8$} & M & 65 & $11(16.9)$ & 55 & $20(36.4)$ & $33(60.0)$ \\
\hline & $\mathrm{F}$ & 58 & $12(20.7)$ & 51 & $25(49.0)$ & $21(41.2)$ \\
\hline & $\mathrm{T}$ & 123 & $23(18.7)$ & 106 & $45(42.5)$ & $54(50.9)$ \\
\hline \multirow[t]{3}{*}{$9-11$} & M & 64 & $16(25.0)$ & 51 & $28(54.9)$ & $37(72.5)$ \\
\hline & $\mathrm{F}$ & 72 & $11(15.3)$ & 55 & $34(61.8)$ & $36(65.5)$ \\
\hline & $\mathrm{T}$ & 136 & $27(19.9)$ & 106 & $62(58.5)$ & $73(68.9)$ \\
\hline \multirow[t]{3}{*}{$12-14$} & M & 81 & $16(19.8)$ & 78 & $45(57.7)$ & $65(83.3)$ \\
\hline & $\mathrm{F}$ & 71 & $8(11.3)$ & 67 & $42(62.7)$ & $49(73.1)$ \\
\hline & $\mathrm{T}$ & 152 & $24(15.8)$ & 145 & $87(60.0)$ & $114(78.6)$ \\
\hline \multirow[t]{3}{*}{$\geq 15$} & M & 13 & $3(23.1)$ & 13 & $7(53.9)$ & $12(92.3)$ \\
\hline & $\mathrm{F}$ & 12 & $2(16.7)$ & 12 & $8(66.7)$ & $10(83.3)$ \\
\hline & $\mathrm{T}$ & 25 & $5(20.0)$ & 25 & $15(60.0)$ & $22(88.0)$ \\
\hline \multirow[t]{3}{*}{ Total } & M & 255 & $47(18.4)$ & 228 & $104(45.6)$ & $161(70.6)$ \\
\hline & $\mathrm{F}$ & 232 & $33(14.2)$ & 204 & $112(54.9)$ & $122(59.8)$ \\
\hline & $\mathrm{T}$ & 487 & $80(16.4)$ & 432 & $216(50.0)$ & $283(65.5)$ \\
\hline
\end{tabular}

Microhaematuria varied significantly across age groups $(\mathrm{P}<0.05)$ but showed no significant variation with gender $(\mathrm{P}>0.05)$. The overall prevalence of proteinuria is $65.5 \%$ with the least $(40.0 \%)$ and highest $(88.0 \%)$ prevalence recorded in age groups 3-5 and 15-19 years respectively. The difference in prevalence of proteinuria between age groups was statistically significant $(\mathrm{P}<0.05)$. Prevalence of proteinuria was significantly higher in male subjects $(70.6 \%)$ than in the female subjects $(59.8 \%)$
$(\mathrm{P}<0.05)$. The overall proportion of the population with proteinuria ranging from none $(<0.1 \mathrm{~g} / \mathrm{L})$ to trace urinary quantity $(<0.3 \mathrm{~g} / \mathrm{L})$ was $48.5 \%$ while $51.5 \%$ of the population had proteinuria $\geq 0.3 \mathrm{~g} / \mathrm{L}$. Most of the male subjects showed higher proportion of pathologic urinary proteinuria $(56.3,65.7,100 \%)$ than their female counterparts $(43.8,34.3,0.0 \%)$ in the $0.3,3.0,5.0 \mathrm{~g} / \mathrm{L}$ categories respectively (Table 3 ). 
Table 3. Severity of proteinuria in the study population $(n=210)$

\begin{tabular}{llll}
\hline $\begin{array}{l}\text { Proteinuria } \\
\text { Gradients }(\mathrm{g} / \mathrm{L})\end{array}$ & $\begin{array}{l}\text { Male } \\
\text { Number }(\%)\end{array}$ & $\begin{array}{l}\text { Female } \\
\text { Number }(\%)\end{array}$ & $\begin{array}{l}\text { Total } \\
(\text { overall } \%)\end{array}$ \\
\hline$<0.1(-\mathrm{ve})$ & $10(31.3)$ & $22(68.8)$ & $32(15.2)$ \\
$<0.3($ Trace $)$ & $46(65.7)$ & $24(34.3)$ & $70(33.3)$ \\
$0.3(1+)$ & $36(56.3)$ & $28(43.8)$ & $64(30.5)$ \\
$1.0(2+)$ & $23(65.7)$ & $12(34.3)$ & $35(16.7)$ \\
$3.0(3+)$ & $1(100)$ & $0(0.0)$ & $1(0.5)$ \\
$5.0(4+)$ & $4(50.0)$ & $4(50.0)$ & $8(3.8)$ \\
Total $(\mathrm{n})$ & 120 & 90 & 210 \\
\hline
\end{tabular}

The most sensitive (80.3\%) Schistosoma morbidity indicator was proteinuria while macrohaematuria was the least sensitive $(24.8 \%)$ indicator of infection due to S. haematobium. However, microhaematuria which recorded higher values in other diagnostic parameters compared to proteinuria showed overall highest diagnostic accuracy of $76.2 \%$ (Table 4).

Table 4. Diagnostic performance of indirect screening methods used for urogenital schistosomiasis

Diagnostic Parameters

\begin{tabular}{lllllll} 
Diagnostic Predictors & Sensitivity & Specificity & PPV $^{\text {a }}$ & NPV $^{b}$ & Accuracy & Reliability \\
\cline { 2 - 6 } Macrohaematuria & 24.8 & 94.7 & 86.3 & 48.7 & 54.8 & 0.144 \\
Microhaematuria & 73.3 & 80.0 & 82.4 & 69.9 & 76.2 & 0.531 \\
Proteinuria & 80.3 & 53.4 & 68.9 & 67.8 & 68.5 & 0.337 \\
Microscopy & 100 & 100 & 100 & 100 & 100 & 1.000 \\
\hline
\end{tabular}

Note a- positive predictive value, $b$ - negative predictive value

\section{Discussion}

The results of this study confirm the active transmission of $S$. haematobium in the study area. The public health implication of the disease is high enough to attract appropriate interventions like mass drug administration and provision of safe water. The overall prevalence of urogenital schistosomiasis (57.1\%) reported in this study is higher than Nigerian estimated mean prevalence $39.1 \%{ }^{2}$ and records from other African countries ${ }^{15,16}$. In moderate-to-high Schistosoma endemic regions, infection usually varies with age and gender. The heterogeneity in exposure influenced by behaviour, culture and social factors, the development of acquired immunity, as well as, physiological changes during puberty are factors that influence susceptibility to the parasite ${ }^{17}$. It is therefore of particular note that in the study area, this typical age-related profile of egg-positive cases appeared, being concordant with a typical endemic area. The age-related infection pattern is similar to other studies conducted in Nigeria ${ }^{18,19}$ but clearly deviated from other studies that reported significant differences in sex-related prevalence ${ }^{3}$. The lack of association between infection and ages of the subjects could be due to equal dependent on natural water bodies in such low resource community with poor water development.

The high prevalence of microhaematuria and proteinuria is similar to a study conducted in Minna, Niger State, Nigeria ${ }^{20}$. These two morbidity indicators are recognized clinical features of $S$. haematobium infection ${ }^{21}$. Both symptoms are indicators of damage in the urinary tract and kidney ${ }^{20}$. Inconclusive evidence has suggested S. haematobium associated glomeruli pathology. When the glomeruli are damaged, protein and often red blood cells leak into the urine. Although, at the present, the precise origin and clinical significance of the proteinuria observed in S. haematobium infection remains unknown ${ }^{22}$. High prevalence of glomerulonephritis had been reported in areas of the tropic where urogenital schistosomiasis is also common, however 
its relationship to $S$. haematobium remain unclear $^{23}$. The occurrence of high proportion of pathologic urinary proteinuria $(\geq 0.3 \mathrm{~g} / \mathrm{L})$ in the current study may suggest urogenital schistosomiasis involvement in inducing glomeruli pathology resulting in abnormal urinary protein excretion. This effect being more pronounced in the male subjects could be due to higher intensity of infection due to $S$. haematobium in the group compared to their female counterparts.

The degree of microhaematuria and proteinuria detectable by chemical reagent strip observed to correlate significantly with microscopy is also similar to the findings ${ }^{18}$. The association of these symptoms with urogenital schistosomiasis had been widely documented $^{24-26}$. The high sensitivity for haematuria and proteinuria reported in this study conforms favourably with earlier reports ${ }^{27-29}$. Macrohaematuria was the most specific but least sensitive, although it has the benefit of not requiring reagent strips. Its gender disparity, however, needs to be considered if using this test, with females requiring additional test ${ }^{30}$.

The inability to generalize result in other population groups since the participants constituted only school pupils and use of single urine sample for both microscopy and morbidity screening are the potential limitations of the study.

The present study shows that microhaematuria is the most accurate and reliable indirect diagnostic method. This is as a result of its high specificity for negative results and high positive predictive value for positive results. The high sensitivity values reflect the usefulness of these diagnostic indices as morbidity indicators of $S$. haematobium in an endemic area. It is also worth mentioning that a combination of proteinuria and microhaematuria may be more efficient in infection diagnosis than a single variable.

\section{Acknowledgements}

This study is financed by MacArthur Multidisciplinary Grant of University of Ibadan, Ibadan, Nigeria. Many thanks to the Education Authorities of Yewa North Local Government Area of Ogun State, Southwestern Nigeria, Head Teachers, parents and pupils of the participating schools for permission to carry out this study.

\section{References}

1. Steinmann P, Keiser J, Bos R, Tanner M and Utzinger J. Schistosomiasis and water resources development: systematic review, meta-analysis, and estimates of peo- ple at risk. Lancet Infectious Diseases 2009; 6(7), 411-425. 2. Schur N, Hürlimann E, Garba A, Traoré MS, Ndir $O$ and Ratard RC. Geostatistical model-based estimates of schistosomiasis prevalence among individuals aged $\leq 20$ years in West Africa. PLoS Neglected Tropical Diseases 2011;5: e1194.

3. Okoli EI and Odaibo AB. Urinary schistosomiasis among school children in Ibadan, an urban community in Southwestern Nigeria. Tropical Medicine and International Health 1999;4(4): 308-315.

4. Oladejo SO and Ofoezie IE. Unabated schistosomiasis transmission in Erinle River Dam, Osun state, Nigeria: evidence of neglect of environmental effects of development project. Tropical Medicine and International Health 2006;11:843-850.

5. Ekpo UF, Mafiana CF, Adeofun CO, Solarin A and Idowu AB. Geographical information system and predictive risk maps of urogenital schistosomiasis in Ogun State, Nigeria BMC Infectious Diseases 2008; 8:74.

6. Morenikeji OA and Idowu BA. Studies on the Prevalence of Urinary Schistosomiasis in Ogun State, SouthWestern Nigeria. West African Journal of Medicine, 2011; 30(1): 62-65.

7. Rollinson DA. Wake up call for urogenital schistosomiasis: reconciling research effort with public health importance. Parasitology 2009;136:1593-1610.

8. Brooker $\mathrm{S}$ and Utzinger J. Integrated disease mapping in a polyparasitic world. Geospatial Health 2007; 1:141-6 9. French MD, Rollinson D, Basáñez MG, Mgeni AF, Khamis IS and Stothard JR. School-based control of urogenital schistosomiasis on Zanzibar, Tanzania: monitoring micro-haematuria with reagent strips as a rapid urological assessment. Journal of Pediatric Urology 2007; 3:364-368.

10. Ugbomoiko US, Dalumo V, Ariza L, Bezerra FSM and Heukelbach J. A simple approach improving the performance of urine reagent strips for rapid diagnosis of urogenital schistosomiasis in Nigerian schoolchildren. Memorias do Instituto Oswaldo Cruz 2009;104:45661.

11. Salawu OT and Odaibo AB. Preliminary study on ecology of Bulinus jousseaumei in Schistosoma haematobium endemic rural community of Nigeria. African Journal of Ecology 2012;1-6 (early online view)

12. Naing L, Winn T and Rusli BN. Practical issues in calculating the sample size for prevalence studies. Archive of Orofacial Science 2006; 1(1):9-14.

13. Hassan A, Ntiaidem U, Morenikeji O, Nwuba R, Anumudu C, Adejuwon S, Salawu O, Jegede A and Odaibo A. Urine turbidity and microhaematuria as rapid 
assessment indicators for Schistosoma haematobium infection among school children in endemic areas. American Journal of Infectious Diseases 2012; 8(1): 60-64

14. Briand V, Watier L, Le Hesran J-Y, Garcia A, Cot M. Coinfection with Plasmodium falciparum and Schistosoma haematobium: protective effect of schistosomiasis on malaria in Senegalese children? American Journal of Tropical Medicine and Hygiene 2005; 72: 702-707.

15. Koukounari A, Touré S, Donnelly CA, Ouedraogo A, Yoda B, Ky C, Kaboré M, Bosqué-Oliva E, Basáñez M-G, Fenwick A and Webster JP. Integrated monitoring and evaluation and environmental risk factors for urogenital schistosomiasis and active trachoma in Burkina Faso before preventative chemotherapy using sentinel sites BMC Infectious Diseases, 2011;11:191

16. Stothard JR, Khamis IS, Blair L, Nyandindi US, Kane RA, Johnston DA, Webster BL and Rollinson D. Parasitological and malacological surveys reveal urogenital schistosomiasis on Mafia Island, Tanzania to be an imported infection, 2012; http://dx.doi.org/10.1016/j. actatropica.2012.09.006

17. King CL. Initiation and regulation of disease in schistosaomiasis. In AAF Mahmoud, Schistosomiasis, Imperial College Press, London, 2001; 213-264.

18. Okon OE, Udoutun MF, Oku EE, Nta AI, Etim SE, Abraham JJ and Akpan PA. Prevalence of urinary schistosomiasis in Abini community, Biase local government area, Cross river State, Nigeria. Nigeria Journal Parasitology 2007;28(1): 28-31.

19. Ugbomoiko US, Ofoezie IE, Okoye IC and Heukelbach J. Factors associated with urinary schistosomiasis in two peri-urban communities in south-western Nigeria. Annals of Tropical Medicine and Parasitology 2010;104(5):409-419

20. ChidozieEU and DaniyanSY. Urinary schistosomiasis epidemiological survey of urinary schistosomiasis among children in selected schools: A preliminary study in Minna, Nigeria. African Journal of Biotechnology 2008; 7(16):2773-2776

21. Wikins HA. The significance of proteinuria and hae- maturia in Schistosoma haematobium infection. Transactions of the Royal Society of Tropical Medicine 1979;73:74-80.

22. Houmsou R, Kela S, Suleiman M and Ogidi J. Urine colour as a rapid assessment indicator in evaluating the prevalence of Schistosoma haematobium infection in two endemic areas of Benue State-Nigeria. The Internet Journal of Tropical Medicine 2009; 6(1)

23. Elissa V. Measuring micro-albuminuria: an innovative approach to estimating intensity of Schistosoma haematobium infection in Zanzibari school children. Working Paper Series, Harvard Center for Population and Development Studies 2004; 14(5).

24. Chugh KS and Sakuja V. Glomerular diseases in the tropics. American Journal of Nephrology, 1990; 10(6), 437450.

25. Laven JS, Vleugels MP, Dofferhoff AS and Bloembergen P. Schistosomiasis as a cause of vulvar hypertrophy. European Journal of Obstetrics, Gynecology and Reproductive Biology 1998;79: 213-216.

26. Traquinho GA, Quinto LE, Nala RM, Gama VR and Corachan M. Schistosomiasis in northern Mozambique. Transactions of the Royal Society of Tropical Medicine and Hygiene 1998;92, 279-281.

27. Nmorsi OPG, Egwunyenga OA and Okolo OE. Schistosoma haematobium infections in two rural communities in EdoState,Nigeria. South East Asian Journal of Tropical Medicine and Public Health 2001;32(3): 570-574.

28. Brouwer KC, Munatsi A, Ndhlovu PD, Wagatsuma Y, Shiff CJ. Urinary schistosomiasis in Zimbabwean school children: predictors of morbidity. African Health Science 2004; 4:115-118.

29. Fatiregun $\mathrm{AA}$, Osungbade $\mathrm{KO}$ and Olumide EA. Diagnostic performance of screening methods for urinary schistosomiasis in a school-based control programme, in Ibadan, Nigeria. Journal of Community Medicine and Primary Health Care 2005; 17(1):24-27

30. Ba'amer AA. Two Practical and Cost Effective Methods for Urinary Schistosomiasis Screening in Yemeni School children. Iranian Journal of Public Health 2009; 38(3):78-83 